\title{
A (POUCO CONHECIDA) CONTRIBUIÇÃO DE BRENTANO PARA AS PSICOTERAPIAS HUMANISTAS ${ }^{1}$
}

\author{
The (Little Known) Contribution of Brentano for Humanistic Psychotherapies \\ La (Poco Sabida) Contribución de Brentano para las Psicoterapias Humanistas
}

Georges Daniel Janja Bloc Boris

\begin{abstract}
Resumo: Este texto se propõe a discutir, entre aqueles vinculados à fenomenologia, o estranho fato de que, ao contrário do que ocorre em relação a Husserl, Heidegger, Sartre ou Merleau-Ponty, poucos parecem reconhecer a importante contribuição de Franz Brentano para as psicoterapias humanistas. Embora não fosse psicólogo, Brentano se dedicou à Psicologia e, como precursor da fenomenologia, foi um desbravador de questões fundamentais que, atualmente, perpassam as bases epistemológicas e filosóficas das abordagens fenomenológicas e humanistas em psicoterapia. Assim, o texto aborda sua teoria da intencionalidade, a Psicologia do Ato e a Filosofia do Presente como contribuições significativas à prática das psicoterapias humanistas.
\end{abstract}

Palavras-chave: Fenomenologia; Brentano; Psicoterapias humanistas; Psicologia.

Abstract: This text is proposed to discuss, between those who are linked to phenomenology, the strange fact of that, in contrast of what happens to Husserl, Heidegger, Sartre or Merleau-Ponty, few of them seem to recognize the important contribution of Franz Brentano for humanistic psychotherapies. Although he was not a psychologist, Brentano was dedicated to psychology and, as a precursor of phenomenology, he was a pioneer of fundamental questions that, currently, cross the epistemological and philosophical bases of phenomenological and humanistic approaches in psychotherapy. Thus, the text discusses his theory of intentionality, the Act-Psychology and the Philosophy of the Present as meaningful contributions to the practice of humanistic psychotherapies.

Keywords: Phenomenology; Brentano; Humanistic psychotherapies; Psychology.

Resumen: Este texto se propone a discutir, entre los que se vinculan à la fenomenología, el hecho extraño de que, al contrario de lo que sucede en relación a Husserl, Heidegger, Sartre y Merleau-Ponty, pocos parecen reconocer la contribución importante de Franz Brentano para las psicoterapias humanistas. Aunque él no era psicólogo, Brentano estuvo dedicado a la psicología y, como precursor de la fenomenología, era un pionero de cuestiones fundamentales que, actualmente, cruzan las bases epistemológicas y filosóficas de los enfoques fenomenológicos y humanistas en la psicoterapia. Así, el texto discute su teoría de la intencionalidad, la Psicología del Acto y la Filosofía del Presente como contribuciones significativas a la práctica de las psicoterapias humanistas.

Palabras-clave: Fenomenología; Brentano; Psicoterapias humanistas; Psicología.

Os objetivos dos esforços que acabamos de descrever não são nem os últimos, nem os supremos objetivos de uma elucidação fenomenológica do conhecimento em geral. Por mais extensas que sejam as nossas análises, o domínio extraordinariamente frutífero do pensar e do conhecer mediatos permaneceu quase completamente não elaborado; a essência da evidência mediata e de seus correlatos ideais continua sem uma elucidação suficiente. Ainda assim, acreditamos que as nossas pretensões não foram insignificantes, e esperamos ter desnudado os mais básicos e, por sua própria natureza, primeiros fundamentos da crítica do conhecimento. É preciso fazer uso, também na crítica do conhecimento, daquela modéstia que pertence à

\footnotetext{
1 Trabalho apresentado ao II Congresso Sul Brasileiro de Fenomenologia \& II Congresso de Estudos Fenomenológicos do Paraná, de 2 a 4 de junho de 2011, na Universidade Federal do Paraná (UFPR), em Curitiba.
}

essência de toda investigação científica. (...) As análises que seguem mostrarão que mesmo um trabalho epistemológico tão modesto terá que superar ainda uma enorme quantidade de dificuldades, ou melhor, terá ainda quase tudo a fazer.

Husserl, em Investigações Lógicas (1900-1901/1980)

\section{Introdução}

Franz Clemens Honoratus Hermann Brentano era alemão e lecionou em Würzburg e na Universidade de Viena. Em 1864, foi ordenado padre, mas questionou a doutrina da infalibilidade papal, abandonando a Igreja em 1873. Sua Filosofia era nitidamente empírica em seu método. Os trabalhos mais importantes de Brentano estão voltados ao campo da Psicologia, por ele definida como ciência dos fenômenos psíquicos ou da consciência. Os 
objetos de seus estudos não foram, porém, os estados, mas os atos e processos psíquicos. Segundo ele, o fenômeno psíquico se distingue dos demais por se referirem sempre a um objeto, bem como a um conteúdo de consciência, por meio de mecanismos puramente mentais. À Psicologia, caberia, então, investigar os diversos modos pelos quais a consciência institui suas relações com os objetos nela existentes, descrevendo a natureza de sua relação, bem como o modo de existência de tais objetos. Seu trabalho mais importante publicado em vida foi $A$ Psicologia Segundo o Ponto de Vista Empírico, de 1874. Foi o mestre de Edmund Husserl, sendo um dos precursores da fenomenologia. Ele é mais conhecido por reintroduzir o conceito escolástico da intencionalidade na Filosofia e proclamá-la como a marca característica dos fenômenos psíquicos. Seus ensinamentos, especialmente sua Psicologia descritiva, influenciaram o movimento fenomenológico no século XX. O significado das contribuições de Brentano para a Filosofia e a Psicologia contemporâneas é ainda estranhamente subestimado. A fenomenologia seria inconcebível sem ele. Ele foi o mestre de Husserl, influenciando, também, Scheler e Heidegger. Seu método tem uma notável semelhança, em muitos aspectos, com os procedimentos do empirismo dos dias de hoje (Crisholm \& Simons, 1998).

\section{A Teoria da Intencionalidade}

A primeira preocupação de Brentano no campo da Psicologia era encontrar uma característica que separasse os fenômenos psicológicos dos físicos. Foi a partir de tal tentativa que ele desenvolveu sua doutrina célebre da intencionalidade como componente determinante dos fenômenos psicológicos. O termo "intencionalidade" é de crucial importância: todo fenômeno psíquico é caracterizado por aquilo que os escolásticos da Idade Média chamavam de in-existência (ou existência em, dentro de) intencional de um objeto na consciência, ou o que poderíamos chamar de referência (Beziehung) a um conteúdo, ou, ainda, de direcionamento (Richtung) a um objeto. Aqui, "in-existência intencional" significa, literalmente, a existência de uma 'intentio' dentro do que pretende ser, como se encaixado nele. Ou seja, referência a um objeto é, portanto, a característica decisiva e indispensável do psíquico: na representação (Vorstellung), algo é representado; no julgamento, algo é confirmado ou rejeitado; no desejo, desejamos algo ou alguém etc. Tal "in-existência intencional” é peculiar somente aos fenômenos psíquicos. Os fenômenos físicos não apresentam nada parecido, sendo caracterizados, por outro lado, como a falta de tal referência. Portanto, podemos definir os fenômenos psíquicos como aqueles que contêm objetos em si mesmos. Também deve ficar claro que os fenômenos psicológicos de Brentano são sempre atos ou processos, pois envolvem as experiências dos sujeitos, bem como seus estados de consciência, o que, então, viria a se tornar um dos padrões básicos para toda análise fenomenológica a partir da Psicologia do Ato de Brentano (Spiegelberg, 1963). O conceito de intencionalidade é, na verdade, um problema entre Brentano e a fenomenologia. De fato, ele, posteriormente, desistiu do termo "intencional" porque acreditava que a sua opinião tinha sido mal interpretada. Portanto, Brentano não usa a expressão "intencionalidade”, mas "in-existência intencional" para distinguir os fenômenos psíquicos dos fenômenos físicos. A cor vermelha é um fenômeno físico, mas, ao se relacionar com a consciência, torna-se um fenômeno psíquico (Münch, 1997).

\section{A Psicologia do Ato de Brentano}

Brentano criou um sistema filosófico que era uma síntese do aristotelismo, do cartesianismo e do empirismo inglês. Este sistema foi modificado de diferentes formas, muitas vezes altamente originais, por seus discípulos, entre os quais, um dos mais importantes foi Edmund Husserl. Em contraposição a Hegel e seus companheiros idealistas, a Escola de Brentano foi muito bem sucedida em associar a sua obra filosófica aos modernos desenvolvimentos no campo das ciências, sobretudo na Psicologia e na Lingüística. Os alunos de Brentano foram responsáveis pela fundação não apenas de novos movimentos filosóficos, como a fenomenologia, mas, também, novas perspectivas de investigação científica, tais como as teorias da Gestalt (Smith \& Burkhardt, 1991). Como filósofo, Brentano discordou das teses do empirismo clássico, do racionalismo e do criticismo kantiano; como psicólogo, rejeitou a tese associacionista do conteúdo da consciência como algo permanentemente real, assim como as idéias de Wundt sobre a consciência como um epifenômeno, reduzido aos seus aspectos fisiológicos. Neste sentido, Brentano denominou sua perspectiva de Psicologia do Ato, argumentando que os fenômenos psíquicos constituem atividades, não conteúdos. Seu método era empírico, mas não experimental, como propunha o empirismo clássico inglês. Afirmava que a Psicologia, à semelhança das ciências da natureza, devia partir da percepção e da experiência, sendo a percepção interna seu principal recurso metodológico. As idéias de Brentano exerceram forte influência nas Filosofias fenomenológicas de Husserl, de Scheler e de Heidegger. Embora questionasse os determinismos biológico e psicológico, não retornou à Psicologia como estudo da alma nem à Filosofia especulativa. Negava a possibilidade de levar o psiquismo ao laboratório, mas propunha que ele fosse abordado de forma empírica, não experimental, abandonando a introspecção como método, já que ela implicava em observação interna, pois aos fenômenos psíquicos cabia a percepção interna. Tal proposta está claramente descrita em seu livro A Psicologia do Ponto de Vista Empírico (Brentano, 1874/1973): 
al como as ciências da natureza, a Psicologia repousa sobre a percepção e a experiência. Mas seu recurso essencial é a percepção interna de nossos próprios fenômenos psíquicos, consistindo em uma representação, um julgamento. O que é prazer e dor, desejo e aversão, esperança e inquietação, coragem e desencorajamento, decisão e intenção voluntária, nunca o saberíamos se a percepção interna de nossos próprios fenômenos não nos lho ensinasse (p. 29).

Brentano considerava a consciência um substrato sintético de representações, sensações, imagens, lembranças e esperanças, denominando-as todas de vivências de fenômenos psíquicos, e, portanto, intencionados. São atos mentais que se referem a objetos exteriores. A intencionalidade constitui a propriedade essencial da vida consciente, indicando uma direção ou tensão da consciência para o objeto. A consciência, na Psicologia do Ato de Brentano, difere da consciência cartesiana, que se desdobra sobre si mesma, enquanto, para Brentano, ela tende sempre a algo no mundo; assim, denominava-a de consciência intencional. A intencionalidade, como a principal característica da consciência, modifica a noção de experiência como estrutura e conteúdo. A consciência intencional constitui uma atividade na qual os fatos físicos diferem dos fatos psicológicos, denominados de fenômenos por Brentano. Os fenômenos psíquicos constituem experiências intencionais, ocorrendo como representações, juízos e fenômenos emocionais. Assim, as idéias de Brentano deram início a uma Psicologia que busca as propriedades da consciência por meio da experiência interna. A partir da sistematização de sua teoria, surgiram a Psicologia da Gestalt, a perspectiva lewiniana e a Psicologia fenomenológica, ou seja, toda a Psicologia cuja ênfase recai sobre a consciência e sua característica fundamental: a intencionalidade (Feijoo, 1999).

Em 1874, ao mesmo tempo em que publicava $A$ Psicologia do Ponto de Vista Empírico, Brentano foi designado professor na Universidade de Viena. Lá, permaneceu até 1895. Gozava de grande popularidade entre os estudantes, entre os quais estavam Sigmund Freud e o filósofo Edmund Husserl. Freud assistiu suas aulas por pelo menos dois anos, exatamente na época em que Brentano publicou seu famoso livro de 1874, no qual seu equacionamento entre o físico e o psíquico, o psicossomático, é mais salientado. O que Freud retirou de Schopenhauer foi, provavelmente, através de Brentano (Cobra, 2001). Em 1884, Husserl, matemático de formação, despertou seu interesse pela Filosofia sob a influência decisiva de Brentano, seu mestre, influência confirmada por Husserl, num texto de 1932: "sem Brentano eu não teria escrito uma única linha de Filosofia” (conforme citado por Maciel, 2003, p. 28). Brentano se opunha à Psicologia experimental, objetiva e mensurante de Wundt. Distinguia a Psicologia da Filosofia, propondo uma Psicologia empírica, tanto subjetiva quanto objetiva e, portanto, rigorosa (Penha, 1985). Brentano recomendou a Husserl que participasse, em 1886, dos cursos, em Halle, do filósofo e psicólogo Stumpf, seu aluno e colaborador direto, onde Husserl se interessou pela percepção e pela imaginação, analisando criticamente os fundamentos introspectivos e experimentais da Psicologia (Depraz, 2007). Ao publicar sua primeira obra, Filosofia da Aritmética, em 1891, Husserl deduziu que teria que retornar à tese de Brentano de que toda representação objetiva está fundamentada numa representação psíquica pré-mental (Capalbo, 2001).

\section{Brentano: Uma Filosofia do Presente nas Psicote- rapias Humanistas}

Poucos sabem, mas a Filosofia do Presente, que afirma que os fenômenos ocorrem aqui e agora e que o presente é a única experiência possível (Boris, 1994), nasceu de Brentano, senão exclusivamente, pelo menos numa parte decisiva. Neste sentido, para Ramón (2006),

(...) os postulados da Psicologia brentaniana não estão menos presentes na Psicologia da Gestalt, de forma geral, e, de forma muito mais nítida, na chamada Gestalterapia. Essa influência explica-se pelo fato de Stumpf (1884-1936) ter sido aluno e colaborador de Brentano (p. 341).

acrescentando que

(...) o método de centrar-se na descrição imediata dos fenômenos das experiências vividas, preconizado pela Fenomenologia e que teve muita influência sobre os teóricos da Gestalt, antes de ser sistematizado por Husserl, já havia sido propugnado por Brentano (p. 341).

Assim, nas psicoterapias humanistas, trabalhar fenomenologicamente significa que a experiência única e imediata de nossos pacientes precede toda tentativa de classificação ou de julgamento. Neste sentido, importa mais que ele descreva sua experiência do que qualquer tentativa nossa, por mais brilhante que possa parecer, de interpretá-la (Ribeiro, 1994). Desta forma,

Brentano propõe é que, ao estudar, por exemplo, a esquizofrenia, não basta apenas conhecer suas bases genéticas e fisiológicas. O saber científico do transtorno deve incluir também sua dimensão psicológica, ou seja, o saber ou significado de ser esquizofrênico vivenciado por cada sujeito esquizofrênico. Os frutos da chamada abordagem fenomenológica da psicopatologia, defendida entre outros por Jaspers, Binswanger e Rogers, confirmam de forma irrefutável a tese brentaniana (Ramón, 2006, p. 344). 
Nas psicoterapias humanistas que têm como base a fenomenologia, o psicoterapeuta busca que as pessoas se deparem com a diferença entre o que é percebido e sentido na situação presente e o que são resíduos do passado. As abordagens humanistas privilegiam a percepção imediata, tratando tanto o que é vivido subjetivamente no presente quanto o que é objetivamente observado, considerando-os dados reais e importantes, o que contrasta com as abordagens que tratam o que o paciente experiencia como meras aparências e usam a interpretação para buscar um pretenso significado verdadeiro (Yontef, 1998). Neste sentido, endosso a posição de Granzotto \& Granzotto (2010) de que,

(...) para Brentano, tão importante quanto explicar, com base em um modelo associacionista ou reflexivo, como opera o intelecto na constituição dos objetos, é descrever quais as 'intenções' (ou de que maneira os sentimentos e as ações) orientam o intelecto (p. 37).

Destaque-se que tais "intenções" nada têm a ver com o sentido corriqueiro que atribuímos ao termo: “(...) a noção brentaniana de intencionalidade não implica a prévia concepção de algum objeto, [mas] apenas a antevisão de um objeto possível” (p. 37). Neste sentido, podemos compreender a importância das "intuições" do psicoterapeuta no trabalho de facilitação da awareness de seus pacientes.

A vivência imediata representa o momento de contato com a realidade, contendo a chave do passado e do futuro e podendo responder às questões mais sutis de como o tempo se concretiza e o espaço se temporaliza: tratase do fenômeno (Ribeiro, 1994). Neste sentido, mais do que afirmar que as psicoterapias humanistas trabalham com o presente, prefiro considerar que elas sempre partem dele, num processo de "presentificação" que atualiza tanto o passado quanto o futuro.

Para adotar uma atitude verdadeiramente fenomenológica, ou seja, para que possa fazer intervenções descritivas sem a priori, é imprescindível que o psicoterapeuta humanista mantenha suas crenças, seus valores e suas necessidades entre parênteses, o que implica numa suspensão de seu juízo, tanto na compreensão quanto na condução da situação psicoterápica. Neste sentido, o psicoterapeuta humanista convida o paciente a descrever sua experiência, a expandir suas fronteiras e a alcançar novos significados para o experiencia no presente da situação psicoterápica e em sua própria vida (Aguiar, 2005). Ribeiro (1985) assim descreve o objetivo da fenomenologia:

(...) ela procura descrever a experiência do modo como ela acontece e se processa. Para tanto é preciso, como diz Husserl, colocar a realidade entre parênteses, suspendendo todo e qualquer juízo. Não afirmar, nem negar, mas antes abandonar-se à compreensão é o modo de atingir a realidade, assim como ela é (p. 47). [...] Assim, podemos deduzir que “(...) o ato psicoterapêutico se converte, então, em um ato criativo, numa busca a dois, se converte numa procura paciente de descrever, de compreender e analisar a realidade como vem ao meu encontro" (p. 57).

\section{Considerações Finais}

De acordo com Granzotto \& Granzotto (2007), há uma ampla gama de influências exercidas pelo criador da Psicologia do Ato, em especial no que se refere à GestaltTerapia, mas, também, sobre diversas áreas da ciência psicológica. Neste sentido, em outra obra (Granzotto \& Granzotto, 2010), consideram que a fenomenologia é uma postura ética, por meio da qual se privilegia a descrição daquilo que se mostra desde si mesmo: mais precisamente, as Gestalten. Da mesma forma, destacam que a fenomenologia husserliana passou por muitas transformações desde a ideia de intencionalidade de Brentano, e, a partir dela, podemos detectar diversas repercussões nas psicoterapias humanistas.

Para Fonseca (2008), a Gestalt-Terapia tem raízes muito claras na fenomenologia, na Filosofia da vida de Nietzsche e, particularmente (pelo menos para os fins deste trabalho), no empirismo de Brentano: "a raiz da Gestalt-Terapia é Brentano, ou melhor, é o empirismo fenomenológico de Brentano”. Para ele, Brentano e Nietzsche são as principais raízes não apenas da Gestalt-Terapia, mas, também, da perspectiva de Heidegger.

Assim, portanto, espero que, a partir desta breve explanação, possamos perceber mais claramente que, apesar das variadas posições e do questionamento da influência da fenomenologia sobre as diversas psicoterapias humanistas, um ponto comum é apontado com frequência: na criação de tais abordagens, a principal raiz é o empirismo de Brentano.

\section{Referências}

Aguiar, L. (2005). Gestalt-Terapia com Crianças: teoria e prática. Campinas: Livro Pleno.

Boris, G. D. J. B. (1994). Noções básicas de fenomenologia. Insight. Psicoterapia (São Paulo). v. 46, pp. 19-25, novembro.

Brentano, F. (1973). Psychology from an Empirical Standpoint. Trad. Antos Rancurello, Linda McAlister. London: Internacional Library of Philosophy (originalmente publicado em 1874).

Maciel, J.C. (2003). Franz Clemens Brentano e a Psicologia. Em Maria Alves de Toledo Bruns \& Adriano Holanda (Orgs). Psicologia e Fenomenologia: reflexões e perspectivas [pp. 27-40]. Campinas: Alínea Editora. 
Capalbo, C. (2001). Fenomenologia e Ciências Humanas. Rio de Janeiro: Âmbito Cultural.

Chisholm, M. \& Simons, P. R. (1998). Brentano, Franz Clemens. In: Routledge Encyclopedia of Philosophy. London: Edward Craig Ed.

Cobra, R. Q. (2001). Franz Brentano. Brasília: http://www.cobra. pages.nom.br. Acesso em 25 de maio de 2011.

Depraz, N. (2007). Compreender Husserl. Rio de Janeiro: Vozes.

Feijoo, A. M. L. C. de (1999). A influência das idéias de Brentano na Psicologia fenomenológico-existencial. In: Jornal Existencial On Line. Edição Especial. Caderno de Temas Existenciais. http://www.existencialismo.org.br/. Acesso em 24 de maio de 2011.

Fonseca, A. H. L. da (2008). Entrevista com Afonso Fonseca. Realizada no Instituto de Gestalt Terapia e Atendimento Familiar. IGT na Rede. Rio de Janeiro: 5 (8), 24.03.2008. Disponível em: http://www.igt.psc.br/ojs/viewarticle. php?id=189. Acesso em 30 de maio de 2011.

Granzotto, M. J. M. \& Granzotto, R. L. M. (2007). Fenomenologia e Gestalt-Terapia. São Paulo: Summus.

Granzotto, M. J. M. \& Granzotto, R. L. M. (2010). Seminário de Fenomenología y Terapia Gestalt. Albacete, Espanha: fevereiro.

Husserl, E. (1980). Investigações Lógicas: sexta investigação. Elementos de uma elucidação fenomenológica do conhecimento. 2. ed. São Paulo: Abril Cultural. Coleção Os Pensadores (originalmente publicado em 1900-1901).

Münch, D. (1997). Franz Brentano. In: Embree, L. et alii (eds.). Encyclopedia of Phenomenology [pp. 74-75]. Dordrecht: Kluwer.

Penha, J. da (1985). O que É Existencialismo. 4. ed. São Paulo: Abril Cultural/Brasiliense. Coleção Primeiros Passos.
Perls, F. S. (2002). Ego, Fome e Agressão: uma revisão da teoria e método de Freud. São Paulo: Summus (originalmente publicado em 1969).

Ramón, S. P. (2006). A importância da Act-Psychology de Franz Brentano. Psicologia: Reflexão e Crítica (Porto Alegre). 19 (2): $340-345$.

Ribeiro, J. P. (1985). Gestalt-Terapia: refazendo um caminho. São Paulo: Summus.

Ribeiro, J. P. (1994). Gestalt-Terapia: o processo grupal. Uma abordagem fenomenológica da teoria do campo e holística. São Paulo: Summus.

Smith, B. \& Burkhardt, H. (1991). Introduction. In: Handbook of Metaphysics and Ontology (Analytica) [pp. XXI-XXII]. Munique: Philosophia Verlag.

Spiegelberg, H. (1963). The Phenomenological Movement. The Hague: Martinus Nijhoff.

Yontef, G. M. (1998). Processo, Diálogo e Awareness: ensaios em Gestalt-Terapia. São Paulo: Summus.

Georges Daniel Janja Bloc Boris - Psicólogo, Mestre em Educação e Doutor em Sociologia pela Universidade Federal do Ceará (UFC). Professor do Programa de Pós-Graduação da Universidade de Fortaleza (UNIFOR). Coordenador do Laboratório de Psicopatologia e Psicoterapia Humanista-Fenomenológica Crítica - APHETO. Psicoterapeuta fenomenológico-existencial, supervisor de estágios em Psicologia Clínica, formador de psicoterapeutas em GestaltTerapia. Endereço Institucional: Universidade de Fortaleza. Avenida Washington Soares, 1321 (Bairro Edson Queiroz). CEP 60811-905. Fortaleza/CE. E-mail: geoboris@uol.com.br; geoboris@unifor.br

Recebido em 15.06.11 Primeira Decisão Editorial em 08.09.11

Aceito em 10.12.11 